\title{
Evaluation of Apricot, Bilberry, and Elderberry Pomace Constituents and Their Potential To Enhance the Endothelial Nitric Oxide Synthase (eNOS) Activity
}

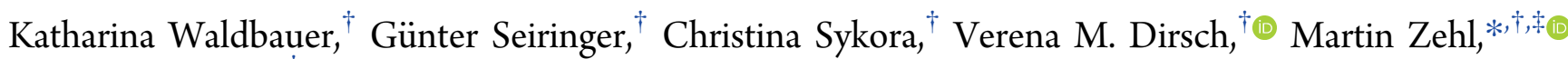 \\ and Brigitte Kopp ${ }^{\dagger}$ \\ ${ }^{\dagger}$ Faculty of Life Sciences, Department of Pharmacognosy, University of Vienna, Althanstrasse 14, 1090 Vienna, Austria \\ ${ }^{\ddagger}$ Faculty of Chemistry, Department of Analytical Chemistry, University of Vienna, Währingerstrasse 38, 1090 Vienna, Austria
}

\section{Supporting Information}

ABSTRACT: Pomace, the press residue from different fruits accumulating as waste product in food industry, contains high amounts of secondary metabolites that could be utilized for health-related applications. This study aims at evaluating the potential of pomaces of apricot, bilberry, and elderberry to serve as a source for endothelial nitric oxide synthase (eNOS)-activating compounds. Five extracts obtained from the lyophilized pomace of apricot and elderberry with solvents of different polarity were found to enhance A23187stimulated eNOS activity when tested at $50 \mu \mathrm{g} / \mathrm{mL}$ in an $\left[{ }^{14} \mathrm{C}\right]$-L-arginine to $\left[{ }^{14} \mathrm{C}\right]$-L-citrulline conversion assay in the human endothelium-derived cell line EA.hy926 $(p<0.05)$. The bioassay-guided fractionation of the extracts obtained

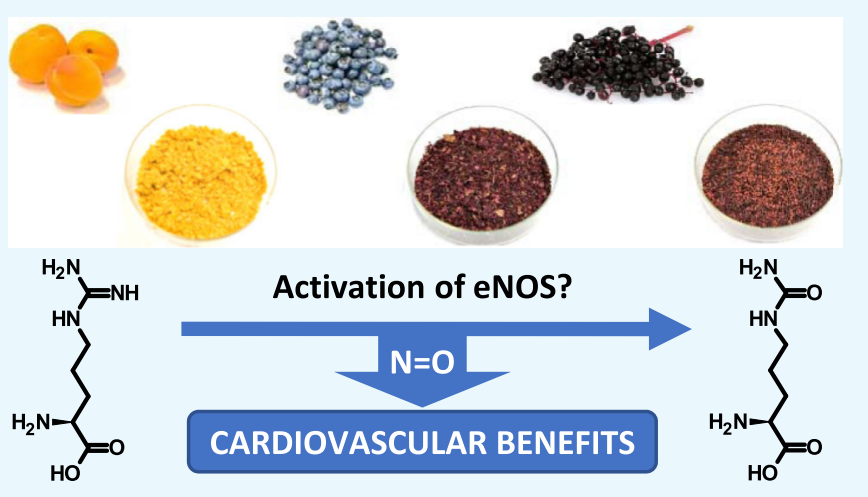
with methanol/water $(70: 30)$ led to several active fractions from apricot pomace $(p<0.05)$ and elderberry pomace $(p<0.01)$. Liquid chromatography-mass spectrometry-based chemical analysis of the extracts and active fractions pointed mainly to triterpenoic acids as active compounds. One particular dihydroxytriterpenoic acid, characteristic for elderberry, was enriched as the main compound in the two most active fractions and might serve as a promising lead structure for further studies.

\section{INTRODUCTION}

Cardiovascular diseases (CVDs) are the leading cause of deaths worldwide, with ischemic heart disease and stroke together accounting for estimated 15.2 million deaths in 2016. The number of deaths due to ischemic heart diseases has significantly increased in the last two centuries, and the death rates are particularly high in wealthy countries. Atherosclerosis has been evaluated as the first manifestation of cardiovascular diseases. A root cause of atherosclerosis is endothelial dysfunction, which is reversible by lifestyle changes, but in most cases leads to more severe conditions. Nitric oxide (NO) seems to play a key role in the maintenance of endothelial homeostasis and vascular health., ${ }^{2,3}$ Vascular NO is mainly produced by the endothelial nitric oxide synthase (eNOS) in the endothelial cell layer. It, inter alia, mediates relaxation in vascular smooth muscle cells and influences their gene transcription/protein expression, inhibits platelet aggregation, and serves as a vascular antioxidant.

Although there are numerous causes and risk factors for CVDs, it is estimated that a high percentage is preventable by means of adaptations to lifestyle, i.e., by avoiding established risk factors such as smoking, excessive alcohol consumption, physical inactivity, and unhealthy diet. A fruit- and vegetablerich diet is associated with a reduced risk for atherosclerosis, ${ }^{4}$ hypertension, ${ }^{5,6}$ and cardiovascular diseases ${ }^{7}$ and indeed compounds from nutritional sources, such as quercetin, ${ }^{8}$ (-)-epicatechin, ${ }^{9}$ or ursolic acid, ${ }^{10}$ have been shown to increase the eNOS activity in vascular endothelial cells. Pomace, the press residue from fruit juice, fruit nectar, or cider industry, still contains high amounts of fruit-derived constituents, ${ }^{11,12}$ suggesting possible health-related applications. So far, some industrial uses for pomaces are already in place, such as pectin extraction, solid-phase fermentation, and animal feed. However, pomaces incur in tons during the fruit press seasons and confront juice producers with storage problems and disposal obligations; thus, further applications are of high interest. This is already under investigation for apple pomace, ${ }^{13,14}$ but should also be considered for other pomaces.

In this study, we aimed to identify and characterize extracts, enriched fractions, or single compounds from apricot (Prunus armeniaca L.), bilberry (Vaccinium myrtillus L.), and elderberry (Sambucus nigra L.) pomace that are able to increase NO production in human endothelium-derived cells. To this end, we tested whether extracts obtained with solvents of different

Received: April 3, 2018

Accepted: August 21, 2018

Published: September 5, 2018 
polarity enhance A23187-stimulated eNOS activation in EA.hy926 cells using the $\left[{ }^{14} \mathrm{C}\right]$-L-arginine to $\left[{ }^{14} \mathrm{C}\right]$-L-citrulline conversion assay (ACCA), in which $\left[{ }^{14} \mathrm{C}\right]$-L-citrulline production serves as a surrogate marker of liberated NO. The chemical characterization of the extracts by liquid chromatography-mass spectrometry (LC-MS) identified several flavonoids, fatty acids, and triterpenoic acids that were previously shown to mediate beneficial effects on eNOS activation in vivo and/or in vitro. Bioassay-guided fractionation led to the conclusion that several di- and trihydroxylated triterpenoic acids are most likely responsible for the increase in A23187-stimulated eNOS activity observed for several fractions and extracts.

\section{RESULTS AND DISCUSSION}

Pomace Extraction. Solvents of different polarity, namely, methanol/water (70:30) ( MeW), ethylacetate (EtOAc), dichloromethane (DCM), and hexane (HEX), were used for extraction. Drug/extract ratios (DERs) are listed in Table 1.

Table 1. Extraction Yields of Fruit Pomaces Using

Pressurized Liquid Extraction (Dionex ASE 200) Expressed as Drug (=Pomace) Extract Ratios (DERs)

\begin{tabular}{lrccc} 
& \multicolumn{4}{c}{ DER } \\
\cline { 2 - 5 } pomace & MeW & EtOAc & DCM & HEX \\
apricot & $1.4: 1$ & $16.0: 1$ & $80.0: 1$ & $96.7: 1$ \\
bilberry & $8.7: 1$ & $12.2: 1$ & $11.3: 1$ & $13.1: 1$ \\
elderberry & $12.7: 1$ & $27.0: 1$ & $23.8: 1$ & $32.3: 1$
\end{tabular}

The MeW extraction resulted in the highest yields for all pomace samples, showing that polar constituents such as carbohydrates make up the largest part of all pomaces. This is particularly the case for apricot pomace, whose extractable matter is predominately composed of polar compounds, whereas the berry pomaces also contain significant amounts of substances that are preferentially extracted with DCM or HEX.

Potential of Pomace Extracts to Enhance eNOS Activation. Twelve extracts from three different fruit pomaces (Table 1) were screened for their ability to enhance A23187stimulated activation of eNOS in the immortalized human endothelium-derived cell line EA.hy926. For this, the $\left[{ }^{14} \mathrm{C}\right]-\mathrm{L}-$ arginine to $\left[{ }^{14} \mathrm{C}\right]$-L-citrulline conversion assay (ACCA) with ascorbic acid $(100 \mu \mathrm{M})$ as positive control (PC) and solvent vehicle (dimethyl sulfoxide, DMSO) as negative control (NC) was applied. The assay was performed $24 \mathrm{~h}$ after cell treatment to allow the detection of influences on eNOS activity on the transcriptional, translational, or post-translational level. ${ }^{15,16}$

When tested at a concentration of $50 \mu \mathrm{g} / \mathrm{mL}$, two apolar extracts (EtOAc, DCM) of apricot pomace significantly increased the eNOS activity compared to the negative control ( $p$ value 0.05 , Figure $1 \mathrm{~A}$ ). None of the bilberry pomace extracts showed any effect on eNOS activity in EA.hy926 cells (Figure 1B), whereas three of four elderberry pomace extracts exhibited a significant increase ( $p$ value 0.05 , Figure 1C). With a 1.5 -fold increase over the negative control, the elderberry pomace $\mathrm{MeW}$ extract showed a higher effect than the DCM and HEX extracts. Cell viability was controlled by the WST-1 assay. The metabolic activity of EA.hy926 cells was impaired by the elderberry HEX extract ( $p$ value 0.01 ), but not by the MeW and DCM extracts (Figure 2). Consequently, the elderberry pomace was considered as the best source for compounds able to enhance eNOS activation.
A

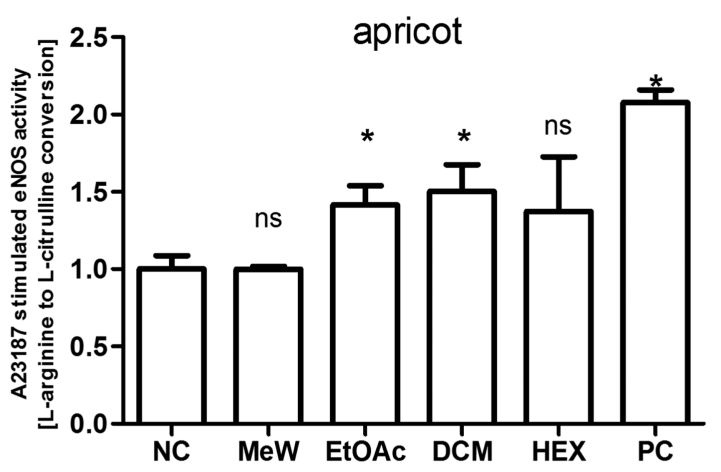

B

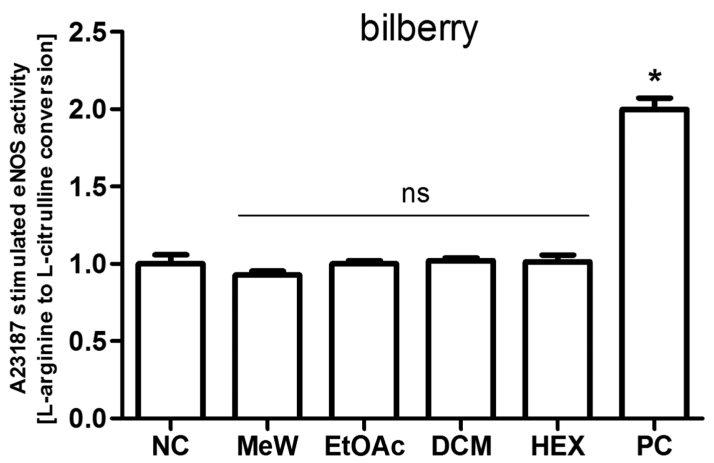

C

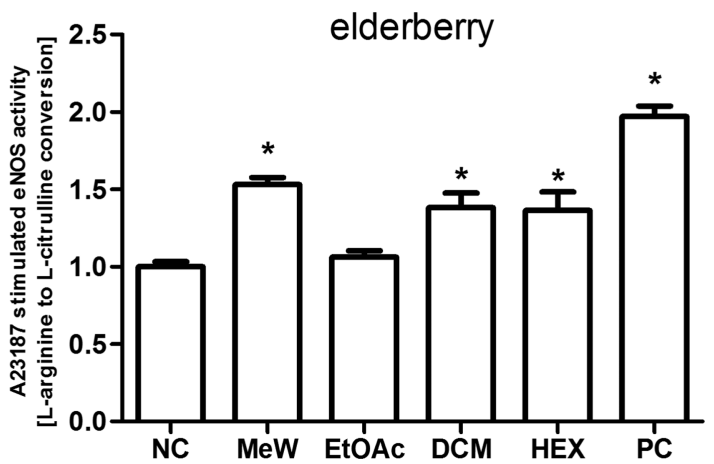

Figure 1. A23187-stimulated eNOS activity in EA.hy926 cells measured by the arginine-citrulline conversion assay (ACCA) after $24 \mathrm{~h}$ of treatment with $50 \mu \mathrm{g} / \mathrm{mL} \mathrm{MeW,} \mathrm{EtOAc,} \mathrm{DCM,} \mathrm{and} \mathrm{HEX}$ extracts of apricot pomace (A), bilberry pomace (B), and elderberry pomace (C). NC, negative control (DMSO); PC, positive control (100 $\mu \mathrm{M}$ ascorbic acid); and one-tailed Mann-Whitney test $(n=3$; mean $\left.\pm \mathrm{SD} ; *_{p}<0.05, *^{*} p<0.01, * * * p<0.001\right)$.

Identification of the Main Compounds in Pomace Extracts by HPLC-DAD-CAD and HPLC-ESI-MS Analysis. The obtained extracts were chemically characterized by high-performance liquid chromatography (HPLC)-diode array detector $(\mathrm{DAD})$-charged aerosol detector $(\mathrm{CAD})$ and HPLC-electrospray ionization (ESI)-MS analyses, and the results are presented in Table 2. All MeW extracts consisted mainly of polar compounds that were not or only weakly retained on the C18 column material (Figure 3), of which only citric acid (1) was identified by comparison with a reference (Figure S4). Several flavonoids and anthocyanins were elucidated in the berry pomace $\mathrm{MeW}$ extracts as less polar 


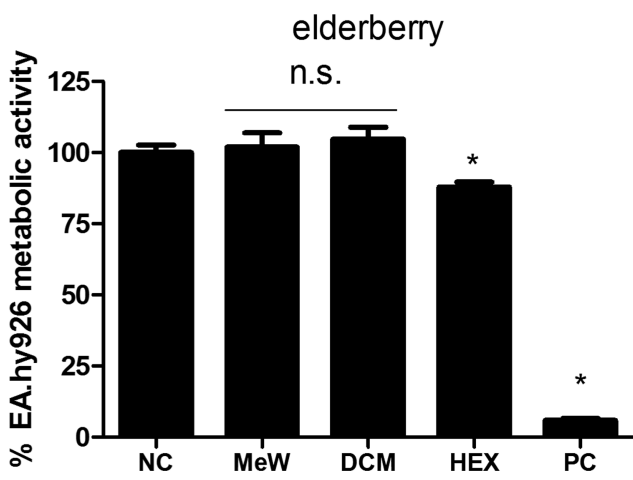

Figure 2. Metabolic activity of EA.hy926 cells measured by the WST-1 assay after $24 \mathrm{~h}$ of treatment with eNOS-activating extracts from elderberry pomace $(=50 \mu \mathrm{g} / \mathrm{mL} \mathrm{MeW}, \mathrm{DCM}$, and HEX extracts of elderberry pomace). NC, negative control (DMSO); PC, positive control (100 $\mu \mathrm{M}$ ursolic acid); one-tailed Mann-Whitney test $(n=3$; mean $\pm \mathrm{SD} ; * p<0.05, * * p<0.01, * * * p<0.001)$.

constituents. The most abundant ones were cyanidin-3glucoside (7), cyanidin-3-sambubioside (2), ${ }^{17}$ and rutin $(\mathbf{1 7})^{18}$ (Figure S5) from elderberry and hyperoside $(\mathbf{1 9})^{19}$ (Figure S6), as well as numerous glycosides of cyanidin, delphinidin, petunidin, peonidin, and malvidin $(3-16)^{20}$ from bilberry.

Triterpenoic acids and fatty acids were already detected in the $\mathrm{MeW}$ extracts (Figure 3) but became the dominant compound classes in all apolar EtOAc, DCM, and HEX extracts (Figure S1).

In all three pomaces, oleanolic acid (42) and ursolic acid (43) were the main triterpenoic acids (Figure S7). Apricot pomace displayed the highest diversity of triterpenoic acid species, with numerous trihydroxy- $(21,22)$, dihydroxy- (27, $31,34$, and 35$)$, and coumaroyldihydroxytriterpenoic acids (28, 32) along with betulinic acid (41) and an acetoxytriterpenoic acid (46) being present particularly in the EtOAc and DCM extract (Figure S1). Another dihydroxytriterpenoic acid (26) was specific for elderberry, whereas both elderberry and bilberry contained relatively low amounts of two oxohydroxytriterpenoic acids $(33,36)$ and a compound tentatively identified as oleanadienoic or ursadienoic acid (45).

Regarding fatty acids, linoleic acid (47) was abundant in the elderberry and bilberry MeW extracts (Figure 3), whereas palmitic acid (48) (Figure S7), oleic acid (49), and stearic acid (53) were found in different concentrations in all apolar extracts (Figure S1).

Particularly in case of the HEX extracts, which generally showed the lowest peak numbers of all extracts, it is likely that additional compounds are present that are too apolar to be detected by the applied LC-MS method.

Bioactivity-Guided Fractionation of the Pomace MeW Extracts. To identify the active components that increase eNOS activity, the methanol/water extracts were chosen for bioassay-guided fractionation for the following reasons: (a) the elderberry $\mathrm{MeW}$ extract was an effective enhancer of eNOS activity, (b) extractable polar bulk compounds, such as carbohydrates and organic acids, may mask bioactivities of lower concentrated compounds in the other MeW extracts, (c) $\mathrm{MeW}$ yielded the highest amounts of extract for all investigated pomaces, (d) methanol comprises comparable dissolving properties to ethanol, a solvent that obliges minor restrictions in food and pharmaceutical industry, and (e) the MeW extracts contained the highest variety of compounds, ranging from very polar to apolar, with most of the compounds detected in the apolar extracts (EtOAc, DCM, HEX) being also present in the $\mathrm{MeW}$ extract, just less abundant.

The fractionation of the MeW extracts from apricot, bilberry, and elderberry pomace by column chromatography on styrene-divinylbenzene resulted in 24,36 , and 30 cumulative fractions, which were screened $(n=1)$ for their potential to increase eNOS activity (Figure S2). Fractions that showed positive effects in the initial ACCA screening were retested twice to reaffirm their bioactivity (Figure 4).

The fractions obtained from the bilberry $\mathrm{MeW}$ extract showed no significant effect on eNOS (Figure 4B) and were thus not further investigated. Fractionation of the apricot pomace $\mathrm{MeW}$ extract yielded fractions able to moderately enhance eNOS activation (Figure 4A). Phytochemical analysis revealed that one of them (fraction 193-202) was enriched in triterpenoic acids $(21,22,23,24,27,28,31,32,34,35,41,42$, and 43 ), particularly the more polar ones already detected in the active EtOAc and DCM extracts (Figure S3). The other, more apolar two fractions (fraction 203-218, fraction 219238) were less complex (Figure S3). One major compound in both fractions was an unknown acetoxytriterpenoic acid (46). Furthermore, an acetoxyhydroxytriterpenoic acid (38) and two fatty acids were identified in fraction 203-218, whereas fraction 219-238 contained an oxidized lipid (44) - besides some unidentified compounds, which were present in both fractions.

From elderberry pomace $\mathrm{MeW}$ extract, a significant increase in eNOS activity was affirmed for seven cumulative fractions (Figure 4C), of which, three most active ones were analyzed in detail (Figure 5). The LC-MS analyses of fractions 211-215 and 216-221 revealed that the most abundant constituent of both is a dihydroxytriterpenoic acid (26), probably $20 \beta$ hydroxyursolic acid according to literature, ${ }^{21,22}$ accompanied by an unknown compound (51). The third active fraction from elderberry pomace $(242-255)$ showed only peaks of very low intensity, such as those of ursolic and oleanolic acid $(42,43)$, and probably contains compounds that escape detection by the applied LC-MS method.

Although the main compounds in these active fractions were elucidated as triterpenoic acids, which are generally known for apoptotic or cytotoxic effects, ${ }^{23}$ the metabolic activity of EA.hy926 cells was actually increased by these fractions (Figure 6).

Because only fatty acids and triterpenoic acids were identified as major compounds in the active $\mathrm{MeW}$ fractions and apolar extracts, their potential to mediate beneficial effects on eNOS activity is discussed.

Considering the identified fatty acids, an increase in basal eNOS activity in EA.hy926 cells was reported upon treatment with palmitic acid (48), ${ }^{24}$ whereas Couloubaly et al. ${ }^{24}$ reported a decrease in basal eNOS activity and eNOS-serine 1177 phosphorylation in EA.hy926 cells after stimulation with 100 $\mu \mathrm{M}$ linoleic acid (47)-albumin complex for $24 \mathrm{~h}$. A contribution of fatty acids to the activity of some fractions and extracts can thus not be excluded.

Triterpenoic acids, which made up the largest fraction of the extractable apolar compounds, comprise various biological activities. $^{23}$ Focusing on eNOS activation, ursolic acid, for instance, was shown to mediate the acute NO-dependent vasorelaxant effects of Lepechinia caulescens (Ortega) Epling 25 and the cardiovascular protective effects of the Chinese drug Danshen (i.e., Salvia miltiorrhiza Bunge). ${ }^{10}$ Increased eNOS 
Table 2. Molecular Weight (MW) and Proposed Structures of the Main Compounds in the Fruit Pomace Extracts

\begin{tabular}{|c|c|c|c|c|c|c|c|c|}
\hline $\begin{array}{l}\text { compound } \\
\text { number }\end{array}$ & $\begin{array}{l}\text { retention time in } \\
\text { gradient program } 1 \\
(\mathrm{GP} 1) \text { or } 2(\mathrm{GP} 2)\end{array}$ & $\mathrm{Da}$ & {$\left[\mathrm{M}-\mathrm{H}_{2} \mathrm{O}+\mathrm{H}\right]^{+}$} & $\begin{array}{l}{[\mathrm{M}+\mathrm{H}]^{+}} \\
\quad \text { or } \mathrm{M}^{+}\end{array}$ & {$[\mathrm{M}+\mathrm{Na}]^{+}$} & {$[\mathrm{M}-\mathrm{H}]^{-}$} & proposed structure & references \\
\hline 1 & $4.2-4.4(\mathrm{GP} 1)$ & 192.0 & & & 215.0 & 190.9 & citric $\operatorname{acid}^{a}$ & \\
\hline 2 & $14.6-15.3(\mathrm{GP} 1)$ & 581.1 & & 581.1 & & & cyanidin-3-O-sambubioside $^{b}$ & 17 \\
\hline 3 & & 465.0 & & 465.0 & & & delphinidin-3-O-galactoside ${ }^{b}$ & 20 \\
\hline 4 & & 465.0 & & 465.0 & & & delphinidin-3-O-glucoside ${ }^{b}$ & 20 \\
\hline 5 & & 435.0 & & 435.0 & & & delphinidin-3-O-arabinoside ${ }^{b}$ & 20 \\
\hline 6 & & 449.0 & & 449.0 & & & cyanidin-3-O-galactoside ${ }^{b}$ & 20 \\
\hline 7 & & 449.0 & & 449.0 & & & cyanidin-3-O-glucoside $^{b}$ & 17,20 \\
\hline 8 & & 449.0 & & 449.0 & & & petunidin-3-O-arabinoside ${ }^{b}$ & 20 \\
\hline 9 & & 479.3 & & 479.0 & & & petundin-3-O-galactoside ${ }^{b}$ & 20 \\
\hline 10 & & 479.3 & & 479.0 & & & petundin-3-O-glucoside ${ }^{b}$ & 20 \\
\hline 11 & & 493.0 & & 493.0 & & & malvidin-3-O-galactoside ${ }^{b}$ & 20 \\
\hline 12 & & 493.0 & & 493.0 & & & malvidin-3-O-glucoside ${ }^{b}$ & 20 \\
\hline 13 & & 463.0 & & 463.0 & & & peonidin-3-O-galactoside ${ }^{b}$ & 20 \\
\hline 14 & & 463.0 & & 463.0 & & & peonidin-3-O-glucoside ${ }^{b}$ & 20 \\
\hline 15 & & 463.0 & & 463.0 & & & malvidin-3-O-arabinoside ${ }^{b}$ & 20 \\
\hline 16 & & 419.0 & & 419.0 & & & cyanidin-3-O-arabinoside ${ }^{b}$ & 20 \\
\hline 17 & $17.0(\mathrm{GP} 1)$ & 610.0 & & 611.0 & & 609.0 & rutin $^{a}$ & 31 \\
\hline 18 & $17.1(\mathrm{GP} 1)$ & 536.1 & 519.0 & & & 535.1 & coumaroyl iridoid isomer ${ }^{b}$ & 32 \\
\hline 19 & $17.4(\mathrm{GP} 1)$ & 464.0 & & 465.0 & & 463.0 & hyperoside $^{a}$ & 19,32 \\
\hline 20 & $9.2(\mathrm{GP} 2)$ & 180.0 & & 181.0 & & & unknown 1 & \\
\hline 21 & $15.2-15.3(\mathrm{GP} 2)$ & 488.3 & & 489.3 & & 487.3 & trihydroxytriterpenoic acid $\mathbf{1}^{b}$ & 33 \\
\hline 22 & $15.8-15.9(\mathrm{GP} 2)$ & 488.3 & & 489.3 & & 487.3 & trihydroxytriterpenoic acid $2^{b}$ & 33 \\
\hline 23 & $17.4(\mathrm{GP} 2)$ & 488.3 & 471.2 & 489.1 & 511.3 & 487.4 & trihydroxytriterpenoic acid 3 & 33 \\
\hline 24 & $17.7(\mathrm{GP} 2)$ & 488.3 & 471.2 & 489.3 & 511.3 & 487.3 & trihydroxytriterpenoic acid 4 & 33 \\
\hline 25 & $19.3(\mathrm{GP} 2)$ & 742.4 & & & 765.3 & 741.4 & PI $(16: 0 / 9: 0(\mathrm{COOH})$ & \\
\hline 26 & $22.1-22.3(\mathrm{GP} 2)$ & 472.1 & 455.2 & & 495.3 & 471.3 & dihydroxytriterpenoic acid $\mathbf{1}^{b}$ & 33 \\
\hline 27 & $24.9-25.0(\mathrm{GP} 2)$ & 472.3 & & 473.3 & & 471.3 & dihydroxytriterpenoic acid $\mathbf{2}^{b}$ & 33 \\
\hline 28 & $24.9-25.0(\mathrm{GP} 2)$ & 634.3 & & 635.3 & & 633.4 & coumaroyl-dihydroxytriterpenoic acid $\mathbf{1}^{b}$ & 33 \\
\hline 29 & $25.3-25.8(\mathrm{GP} 2)$ & 472.1 & 455.2 & & 495.3 & 471.6 & dihydroxytriterpenoic acid $3^{b}$ & 33 \\
\hline 30 & $25.3-25.8(\mathrm{GP} 2)$ & 472.1 & 455.2 & & 495.3 & 471.6 & dihydroxytriterpenoic acid $4^{b}$ & 33 \\
\hline 31 & $26.1-26.2(\mathrm{GP} 2)$ & 472.3 & & 473.3 & & 471.3 & dihydroxytriterpenoic acid $\mathbf{5}^{b}$ & 33 \\
\hline 32 & $26.1-26.2(\mathrm{GP} 2)$ & 634.3 & & 635.3 & & 633.4 & coumaroyl-dihydroxytriterpenoic acid $2^{b}$ & 33 \\
\hline 33 & $26.4-26.5(\mathrm{GP} 2)$ & 470.3 & & 471.3 & & 469.3 & oxohydroxytriterpenoic acid $\mathbf{1}^{b}$ & 33 \\
\hline 34 & $27.3-27.4(\mathrm{GP} 2)$ & 472.3 & & 473.3 & & 471.3 & dihydroxytriterpenoic acid $6^{b}$ & 33 \\
\hline 35 & $28.3-28.4(\mathrm{GP} 2)$ & 472.3 & & 473.3 & & 471.3 & dihydroxytriterpenoic acid $7^{b}$ & 33 \\
\hline 36 & $33.0-33.2(\mathrm{GP} 2)$ & 470.3 & & 471.3 & & 469.3 & oxohydroxytriterpenoic acid $2^{b}$ & 33 \\
\hline 37 & $33.1(\mathrm{GP} 2)$ & 606.3 & 589.3 & & 629.3 & & unknown 2 & \\
\hline 38 & $36.0(\mathrm{GP} 2)$ & 514.3 & & & 537.2 & 513.3 & acetoxyhydroxytriterpenoic acid & \\
\hline 39 & $36.8(\mathrm{GP} 2)$ & 518.3 & 501.3 & & 541.3 & 517.5 & unknown 3 & \\
\hline 40 & $38.2(\mathrm{GP} 2)$ & 518.3 & 501.3 & & 541.3 & 517.5 & unknown 4 & \\
\hline 41 & $38.2-38.4(\mathrm{GP} 2)$ & 456.3 & & 457.3 & & 455.3 & betulinic acid ${ }^{b}$ & 13,33 \\
\hline 42 & $40.1-40.3(\mathrm{GP} 2)$ & 456.3 & & 457.3 & & 455.3 & oleanolic $\operatorname{acid}^{a}$ & 13,33 \\
\hline 43 & $40.4-40.7$ (GP2) & 456.3 & & 457.3 & & 455.3 & ursolic acid $^{a}$ & 13,33 \\
\hline 44 & $40.6(\mathrm{GP} 2)$ & 665.3 & & 666.3 & 688.4 & 664.3 & PC (16:0/9:0(COOH $))$ & \\
\hline 45 & $48.5-48.6(\mathrm{GP} 2)$ & 438.3 & & 439.3 & & 483.5 & ursadienoic or oleanadienoic acid ${ }^{b}$ & 34 \\
\hline 46 & $50.0(\mathrm{GP} 2)$ & 498.3 & & 499.3 & & 497.3 & acetoxytriterpenoic acid & \\
\hline 47 & $55.7(\mathrm{GP} 1)$ & 280.1 & & 281.2 & & 279.1 & linoleic acid $(18: 2)^{a}$ & \\
\hline 48 & $51.4-51.7(\mathrm{GP} 2)$ & 256.2 & & 257.2 & & 255.2 & palmitic acid $(16: 0)^{a}$ & \\
\hline 49 & $51.4-51.7(\mathrm{GP} 2)$ & 282.2 & & 283.2 & & 281.2 & oleic acid $(18: 1)^{b}$ & 35 \\
\hline 50 & $56.0(\mathrm{GP} 2)$ & 460.2 & 443.2 & & 483.3 & 459.2 & unknown 5 & \\
\hline 51 & $56.1(\mathrm{GP} 2)$ & 358.2 & 341.2 & & 381.2 & & unknown 6 & \\
\hline 52 & $57.8-58.0(\mathrm{GP} 2)$ & 462.3 & 445.3 & & & 461.3 & unknown 7 & \\
\hline 53 & 59.7 (GP2) & 284.4 & & & & 283.4 & stearic acid (C18:0) & 36 \\
\hline
\end{tabular}

promotor activity, eNOS mRNA and protein expression, and an increased phosphorylation at eNOS serine 1177 were shown to contribute to the enhanced NO production mediated by ursolic acid. ${ }^{10,26}$ Rios et al. ${ }^{27}$ predicted the affinities of plant-derived triterpenoic acids to two binding pockets of eNOS by computational docking experiments.

However, triterpenoic acids are also known for their inhibition of cell proliferation and their cytotoxicity. He and 


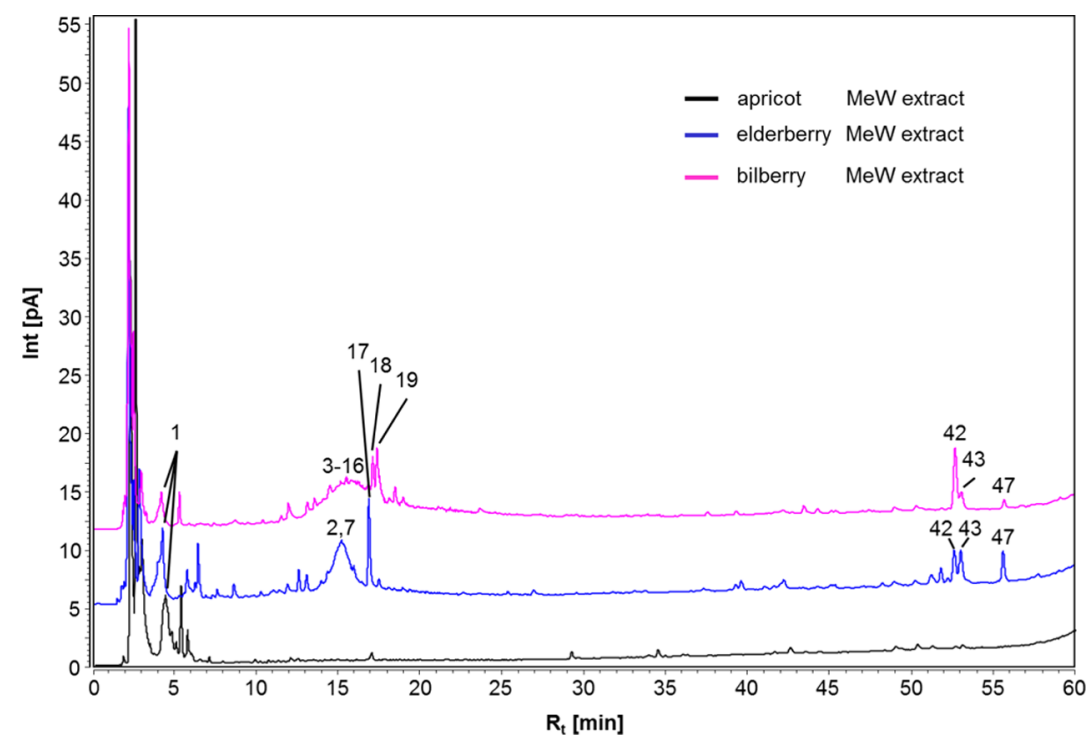

Figure 3. HPLC profiles of the MeW extracts from apricot, elderberry, and bilberry pomace. Column: Hypersil BDS C18 $(250 \times 4.0 \mathrm{~mm} ; 5 \mu \mathrm{m})$; mobile phase A: $\mathrm{H}_{2} \mathrm{O}$, pH $2.8(\mathrm{HCOOH})$; mobile phase $\mathrm{B}$ : ACN $(\mathrm{HCOOH})$; flow rate: $1 \mathrm{~mL} / \mathrm{min}$; column oven: $17^{\circ} \mathrm{C}$; injected volume: $5 \mu \mathrm{L}$; elution gradient: $1-95 \% \mathrm{~B}$ in 60 min; detection: $\mathrm{CAD}$.

$\mathrm{Liu}^{28}$ reported half maximum effective concentrations $\left(\mathrm{EC}_{50}\right)$ for cytotoxicity of nine triterpenoic acids from apple peel in different cancer cell lines between 18.2 and $332 \mu \mathrm{M}$. Yamaguchi et al. ${ }^{29}$ showed that $20 \mu \mathrm{M}$ ursolic acid inhibited the growth of tumorigenic HM-SFME-1 cells to $10 \%$ and of nontumorigenic SFME- 1 cells to $40 \%$ relative to the control. Further, it has been shown that ursolic acid concentrations above $5 \mu \mathrm{M}$ significantly reduce the cell viability of coronary artery endothelial cells. ${ }^{26}$

The fractionation of the apricot and elderberry pomace $\mathrm{MeW}$ extracts hinted toward a higher eNOS-activating potential of fractions rich in di- and trihydroxylated triterpenoic acids compared to that containing predominantly oleanolic and ursolic acid. This result confirms the previous data obtained for apple pomace. ${ }^{16}$ The activity of fractions obtained previously from apple pomace and now from apricot pomace $\mathrm{MeW}$ extract seems to be mediated by a mixture of several triterpenoic acids that are not necessarily active as single substance. In contrast, the two most active fractions from elderberry pomace $\mathrm{MeW}$ extract were of low complexity. The same main compound-a dihydroxytriterpenoic acid (26) that is probably $20 \beta$-hydroxyursolic acid-was detected in both fractions. These fractions clearly did not reduce the cell metabolic activity. The isolation, structure elucidation, and investigation of the mechanism of action of this compound would certainly be of interest but was not achieved in this study due to the low amounts of the relevant fractions.

As outlined above, several abundant compounds of the investigated fruit pomace extracts can be associated with beneficial effects on the activity of eNOS based on in vivo and/ or in vitro studies. The eNOS in the endothelial cell layer is mainly responsible for the release of vascular NO, which protects the cardiovascular system in several ways: it regulates the vascular tone via relaxation of the vascular smooth muscle cells, has antithrombotic effects, serves as a vascular antioxidant, and attenuates the adhesion of leukocytes to the vascular endothelium. Although it is well established and broadly communicated that a fruit- and vegetable-rich diet is associated with a reduced risk for cardiovascular diseases, ${ }^{4-7}$ changing their lifestyle proves to be very difficult to many people. Food supplements that are highly enriched in fruit-derived compounds that enhance eNOS in vivo could be one option in the prevention of cardiovascular diseases. Our results indicate that fruit pomaces might serve as a useful resource for the production of such food supplements, but further studies, particularly in vivo data, are required on the way to develop such a product.

\section{CONCLUSIONS}

In this study, constituents extracted from apricot, bilberry, and elderberry pomaces were analyzed by LC-MS and evaluated on their potential to beneficially influence the activity of eNOS. The majority of the extractable matter is made up of very polar compounds, but only the elderberry methanol/water (70:30) (MeW) extracts enhanced A23187-stimulated eNOS activity in the human endothelium-derived cell line EA.hy926 at $50 \mu \mathrm{g} /$ $\mathrm{mL}$. In addition, four of the more apolar extracts from the apricot and elderberry pomaces were active in the ACCA. The bioassay-guided fractionation of the apricot and elderberry pomace $\mathrm{MeW}$ extracts indicates that di- and trihydroxylated triterpenoic acids contribute strongly to the observed activity, whereas the major constituents oleanolic and ursolic acid are less or not effective. One particular dihydroxytriterpenoic acid from elderberry pomace, probably $20 \beta$-hydroxyursolic acid, might serve as a promising lead structure for further studies. It was highly enriched in fractions that enhanced A23187stimulated eNOS activity at $10 \mu \mathrm{g} / \mathrm{mL}$, but that did not reduce the cell metabolic activity, although triterpenoic acids are generally associated with cytotoxic effects. Provided that our in vitro data can be translated to positive effects in vivo, apricot and particularly elderberry pomaces might become valuable resources for health-related applications, such as the production of food supplements that reduce the risk for cardiovascular diseases.

\section{METHODS}

Reagents. Methanol (MeOH) and hexane (HEX), both AnalaR Normapur, dichloromethane (DCM) and ethyl acetate (EtOAc), both GPR Rectapur, and acetonitrile (ACN) 
A

apricot

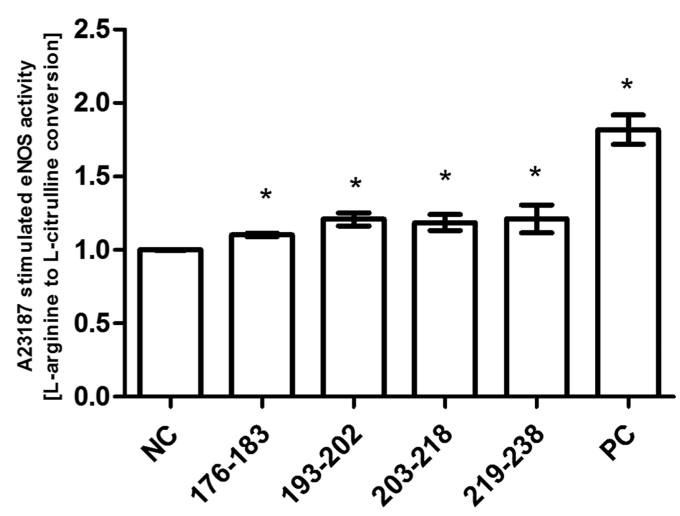

B

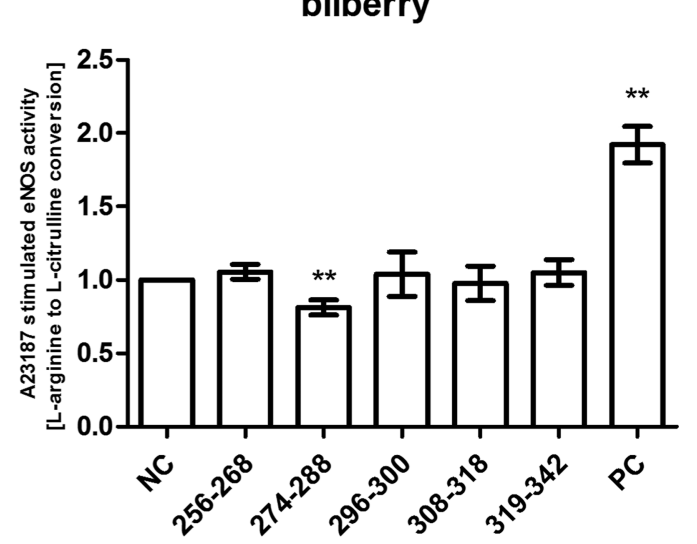

C

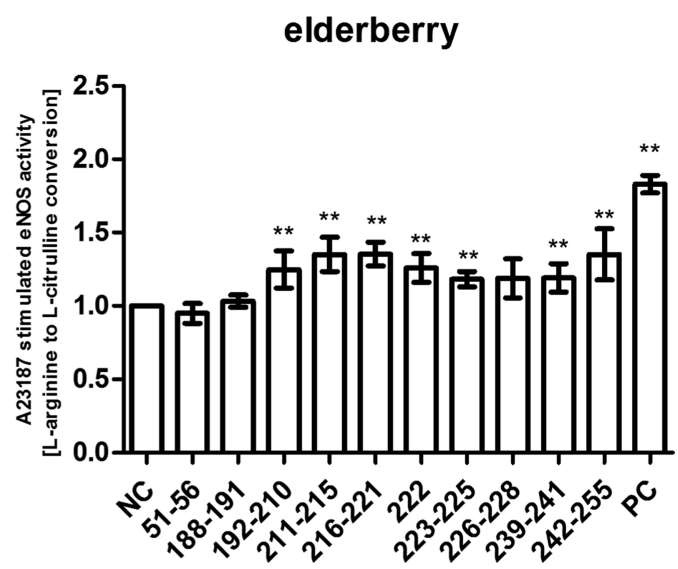

Figure 4. A23187-stimulated eNOS activity in EA.hy926 cells measured by the arginine-citrulline conversion assay (ACCA) after $24 \mathrm{~h}$ of treatment $(10 \mu \mathrm{g} / \mathrm{mL})$ with cumulative fractions obtained from the fractionation of apricot pomace $\mathrm{MeW}$ extract (A), bilberry pomace $\mathrm{MeW}$ extract (B), and elderberry pomace $\mathrm{MeW}$ extract (C). The data from the screening of all fractions are shown in Figure S2. NC, negative control (DMSO); PC, positive control (100 $\mu \mathrm{M}$ ascorbic acid); onetailed Mann-Whitney test $(n=3$; mean \pm SD; $* p<0.05$, ** $p<0.01$, $* * * p<0.001)$.

HiPerSolv Chromanorm for HPLC-CAD-MS analysis were obtained from VWR (Vienna, Austria). Formic acid (purity $>98.0 \%$ ) and conc. ammonia (24\%) were purchased from GattKoller (Absam, Austria). Water, for extraction and phytochem- ical analysis, was deionized and distilled. Betulinic acid (purity 95\%), corosolic acid (purity 90\%), maslinic acid (purity 89\%), oleanolic acid (purity 94\%) and ursolic acid (purity 94\%), cyanidin-3-O-sambubioside (purity 99\%), cyanidin-3-O-glucoside (purity $88 \%$ ), delphinidin-3-O-glucoside (purity $87 \%$ ), malvidin-3-O-glucoside (purity 99\%), peonidin-3-O-glucoside (purity 94\%), and petunidin-3-O-glucoside (purity 99\%) were provided from Phytolab (Vestenbergsgreuth, Germany), hyperoside (purity 99\%), and rutin (purity 99\%) from Extrasynthèse (Lyon, France), and palmitic acid (purity 99\%) and linoleic acid (purity 99\%) from Sigma-Aldrich (St. Louis, MO).

Sample Collection and Preparation. Stone-free apricot pomace, from Obsthof Reisinger (Spitz/Donau, Austria), as well as elderberry pomace and bilberry pomace, both from RAUCH Fruchtsäfte (Rankweil, Austria), was immediately frozen $\left(-20{ }^{\circ} \mathrm{C}\right)$ after pressing in the season 2011 and lyophilized for $48 \mathrm{~h}$ (Zirbus Va Co 5-11) before further processing. The apricot pomace was crushed using pistil and mortar, bilberry pomace was milled (RETSCH mill, sieve 0.5 ), and elderberry pomace was excluded from comminution treatment to avoid the release of cyanogenic glycosides due to the high stone content. ${ }^{30}$ Addition of $20 \%$ diatomaceous earth to the homogeneous pomace powders avoided clotting during the pressurized liquid extraction process.

Extraction. Pressurized liquid extraction of homogenized pomace samples was carried out using an ASE 200 accelerated solvent extraction system (Dionex, Vienna, Austria) with methanol/water (70:30) (MeW), ethylacetate (EtOAc), dichloromethane (DCM), and hexane (HEX) as solvents. For each solvent, 8-10 g pomace or pomace/diatomaceous earthmixture was filled into an $11 \mathrm{~mL}$ extraction cell and extracted in three cycles using the following conditions: preheat time: 5 min; heat time: $5 \mathrm{~min}$; temperature: $40{ }^{\circ} \mathrm{C}$; static extraction: 5 min; flush volume: $0.6 \%$, purge time: $60 \mathrm{~s}$; pressure: $1500 \mathrm{psi}$. The obtained extracts were dried by solvent evaporation and subsequent lyophilization, if necessary.

Fractionation of the MeW Extracts. Pomaces were extracted with $\mathrm{MeW}$ under conditions stated above but using $22 \mathrm{~mL}$ extraction cells filled with $15-17 \mathrm{~g}$ pomace or pomace/ diatomaceous earth-mixture. The obtained pomace MeW extracts were dissolved in $\mathrm{EtOH} 96 \%(\mathrm{v} / \mathrm{v}) /$ water (50:50) and ultracentrifuged. The supernatant was pipetted in portions onto a styrene-divinylbenzene matrix (DIAION-HP 20), which previously has been washed with $\mathrm{EtOH} 96 \%(\mathrm{v} / \mathrm{v})$ and conditioned with $\mathrm{EtOH} 96 \%$ (v/v) $/ \mathrm{H}_{2} \mathrm{O}$ (10:90).

Fractions of $200 \mathrm{~mL}$ were eluted with a series of $\mathrm{EtOH} 96 \%$ $(\mathrm{v} / \mathrm{v}) / \mathrm{H}_{2} \mathrm{O}$ mixtures of decreasing polarity, in the case of elderberry and bilberry pomace, followed by $\mathrm{MeOH}$ and EtOAc. The fractions showing similar thin-layer chromatography (TLC) fingerprints were combined to cumulative fractions. Detailed information is given in Chapter 3 (Supporting Information).

$\left[{ }^{14} \mathrm{C}\right]$-L-Arginine to $\left[{ }^{14} \mathrm{C}\right]$-L-Citrulline Conversion Assay. The $\left[{ }^{14} \mathrm{C}\right]$-L-arginine to $\left[{ }^{14} \mathrm{C}\right]$-L-citrulline conversion assay (ACCA) was performed as described previously. ${ }^{15,16}$ In brief, 5 $\times 10^{5}$ EA.hy926 cells/well were seeded in 6-well plates and cultivated to confluence for 3-4 days. Before stimulation, 100 $\mathrm{U} / \mathrm{mL}$ of bovine liver catalase (Sigma-Aldrich) was added to the culture media. Catalase prevents the accumulation of $\mathrm{H}_{2} \mathrm{O}_{2}$, which originates from reactions of the phenolic plant compounds with cell culture media components and may lead to false-positive results. For the assay, stock solutions of the 


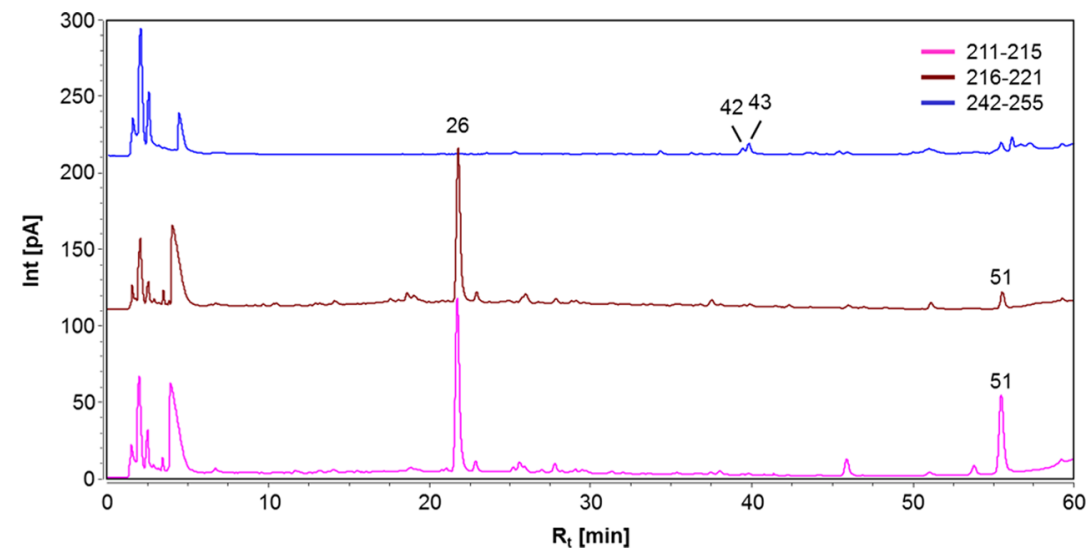

Figure 5. Chromatographic profiles of eNOS-activating fractions from elderberry pomace MeW extract. Column: Hypersil BDS C18 (250 $\times 4.0 \mathrm{~mm}$; $5 \mu \mathrm{m})$; mobile phase A: $\mathrm{H}_{2} \mathrm{O} ; \mathrm{pH} 2.8(\mathrm{HCOOH})$; mobile phase $\mathrm{B}: \mathrm{ACN}(\mathrm{HCOOH})$; flow rate: $1 \mathrm{~mL} / \mathrm{min}$; column oven: $25^{\circ} \mathrm{C}$; injected volume: 5 $\mu \mathrm{L}$; gradient program 2 (GP2): $35-95 \% \mathrm{~B}$ in $60 \mathrm{~min}$; and detection: $\mathrm{CAD}$.

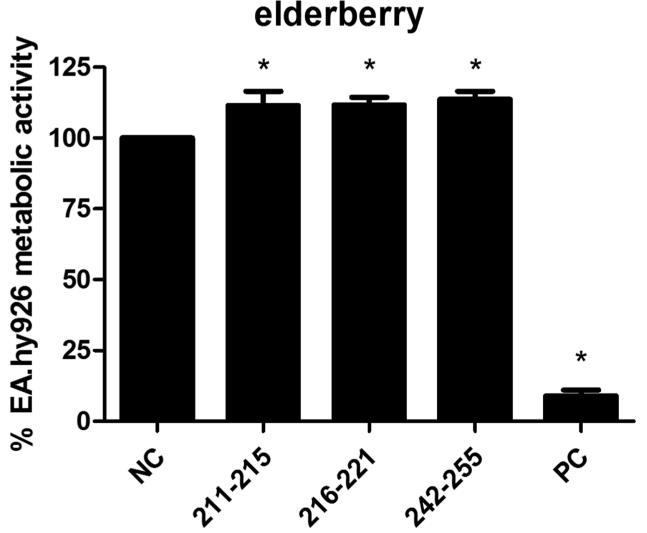

Figure 6. Metabolic activity of EA.hy926 cells measured by the WST-1 assay after $24 \mathrm{~h}$ of treatment $(10 \mu \mathrm{g} / \mathrm{mL})$ with eNOS-activating fractions from elderberry pomace $\mathrm{MeW}$ extract. NC, negative control (DMSO); PC, positive control (100 $\mu \mathrm{M}$ ursolic acid); and one-tailed Mann-Whitney test $\left(n=3\right.$; mean $\pm \mathrm{SD} ; *^{*}<0.05, * * p<0.01$, ***p $<$ $0.001)$.

extracts or fractions in DMSO were freshly diluted into the culture medium. Final DMSO concentrations did not exceed $0.1 \%$. Negative control cells were treated with identical volumes of pure DMSO. Twenty-four hours after stimulation with either DMSO, as a negative control, or the indicated concentrations of the respective extracts and fractions, the medium was removed. The cells were washed and equilibrated for $15 \mathrm{~min}$ with 2-[4-(2hydroxyethyl)-1-piperazinyl]-ethyl sulfonic acid (HEPES) buffer (10 mM 2-[4-(2-hydroxyethyl)-1-piperazinyl]-ethyl sulfonic acid (HEPES), $150 \mathrm{mM} \mathrm{NaCl}, 5 \mathrm{mM} \mathrm{KCl}$ from Carl Roth, $2 \mathrm{mM} \mathrm{MgSO}$, $10 \mathrm{mM}$ glucose, $1.5 \mathrm{mM} \mathrm{CaCl} \cdot 2 \mathrm{H}_{2} \mathrm{O}$ from Sigma-Aldrich, $\mathrm{pH}$ 7.4). Subsequently, $0.32 \mu \mathrm{M}\left[{ }^{14} \mathrm{C}\right]-\mathrm{L}-$ arginine (346 $\mathrm{mCi} / \mathrm{mmol}$, New England Nuclear, Boston, MA) and $1 \mu \mathrm{M}$ calcium ionophore (A23187, Alexis Biochemicals, Paisly, U.K.) were added. After $15 \mathrm{~min}$ of $\left[{ }^{14} \mathrm{C}\right]$-L-citrulline production, the reaction was stopped by washing the cells with ice-cold phosphate-buffered saline (PBS). The cells were lysed with ice-cold ethanol $96 \%(\mathrm{v} / \mathrm{v})$ and subsequently extracted with water. The supernatant was dried under vacuum (SPD 1010 Speed Vac, Thermo Savant). The obtained cell extract was redissolved in $\mathrm{MeOH} / \mathrm{H}_{2} \mathrm{O}(1 / 1)$ and separation of $\left[{ }^{14} \mathrm{C}\right]$ L-arginine and $\left[{ }^{14} \mathrm{C}\right]$-L-citrulline was conducted via TLC (Polygram SIL N-HR, $20 \times 20 \mathrm{~cm}$, Machery-Nagel, Düren,
Germany) using methanol/ammonia conc./chloroform/water (9:4:1:2) as mobile phase. Dried plates were autoradiographed by a phosphoimager (BAS-1800II, Fujifilm, Germany) and AIDA software (raytest, Langenzersdorf, Austria) was used for densitometric analysis. L-Ascorbic acid (100 $\mu \mathrm{M}$, SigmaAldrich) was used as positive control.

Evaluation of Cell Viability. Viable, metabolically active cells convert the tetrazolium salt WST-1 (4-[3-(4-Iodophenyl)2-(4-nitro-phenyl)-2H-5-tetrazolio]-1,3-benzene disulfonate) to a water-soluble formazan derivative with high absorption rates at $440 \mathrm{~nm}$. WST-1 was used according to the protocol given by the supplier (Roche Diagnostics, IN). The evaluation was performed $24 \mathrm{~h}$ after stimulation with the indicated concentrations of the respective extracts or fractions with correction for the self-absorption of the samples. Ursolic acid was used as a positive control.

Statistical Analysis. Raw data from the ACCA and WST-1 assay were normalized to the negative control (NC). Normalized data were incorporated in GraphPad Prism version 4.0 (La Jolla, CA). Significant differences with the NC were calculated using one-tailed Mann-Whitney Test. Shown are the mean values \pm SD of three independent experiments.

Phytochemical Analysis. Sample Preparation. MeW extracts were dissolved in $\mathrm{MeW}$ to a concentration of 5.0 $\mathrm{mg} / \mathrm{mL}$, EtOAc, DCM, and HEX pomace extracts in $\mathrm{MeOH} /$ DMSO (80:20) in a concentration of $8.0 \mathrm{mg} / \mathrm{mL}$. The samples were sonicated for $10 \mathrm{~min}$, centrifuged at $13.4 \times 10^{3} \mathrm{rpm}$, and the supernatant taken for analysis. The precipitate was dried using a centrifugal evaporator (Genevac, Ipswich, U.K.) and weighed for calculating the percentage of dissolved extract, representing the phytochemically characterized part of the extract (Table S1).

Fractions were dissolved in $\mathrm{MeOH} / \mathrm{DMSO}$ (80:20) at concentrations of $8 \mathrm{mg} / \mathrm{mL}$.

HPLC-DAD-CAD and HPLC-MS Analysis. Analyses were carried out on an UltiMate 3000 RSLC-series system (Dionex/ Thermo Fisher Scientific, Germering, Germany) coupled in parallel to a Corona ultra RS charged aerosol detector (CAD, Dionex/Thermo Fisher Scientific) and an HCT 3D quadrupole ion trap mass spectrometer equipped with an orthogonal ESI source (Bruker Daltonics, Bremen, Germany). The separation was performed on an Agilent Hypersil BDS C18, $4.0 \times 250 \mathrm{~mm}$, $5 \mu \mathrm{m}$ column using water with $\mathrm{pH} 2.8$ (formic acid) as mobile phase $\mathrm{A}$ and acetonitrile, modified with the same amount of 
formic acid, as mobile phase B. The HPLC flow rate was 1.0 $\mathrm{mL} / \mathrm{min}$. Gradient program 1 (GP1), used for MeW extracts, consisted of a linear increase from 1\% B to $95 \%$ B in $60 \mathrm{~min}$ at $17{ }^{\circ} \mathrm{C}$ column oven temperature. Gradient program 2 (GP2), conducted for EtOAc, DCM, and HEX extracts, started with a concentration of $35 \%$ mobile phase $\mathrm{B}$, which increased by $1 \%$ per min at $25{ }^{\circ} \mathrm{C}$ column oven temperature. The final mobile phase B concentration in both methods was $95 \%$, which was held for $10 \mathrm{~min}$ to wash the column between the single runs, followed by $10 \mathrm{~min}$ of equilibration at starting conditions of the respective gradient program. As the primary objective was the phytochemical comparison of the different pomace extracts and fractions, the HPLC methods were not further optimized for particular pomace extracts or fractions.

After passing the $\mathrm{DAD}$, the eluate flow was split $4: 1$ between the $\mathrm{CAD}$ and the $\mathrm{MS}$, respectively. The $\mathrm{CAD}$ nebulizer temperature was $35^{\circ} \mathrm{C}$ and the ESI ion source was operated as follows: capillary voltage: $+3.5 /-3.7 \mathrm{kV}$, nebulizer: $26 \mathrm{psi}\left(\mathrm{N}_{2}\right)$, dry gas flow: $9 \mathrm{~L} / \mathrm{min}\left(\mathrm{N}_{2}\right)$, and dry temperature: $340{ }^{\circ} \mathrm{C}$. Positive and negative ions mode multistage mass spectra up to $\mathrm{MS}^{4}$ were obtained in automated data-dependent acquisition (DDA) mode using helium as collision gas, an isolation window of $\Delta m / z=4$, and a fragmentation amplitude of $1.0 \mathrm{~V}$.

\section{ASSOCIATED CONTENT}

\section{S Supporting Information}

The Supporting Information is available free of charge on the ACS Publications website at DOI: 10.1021/acsomega.8b00638.

Detailed information about sample preparation, fractionation, and LC-MS data are given; further chromatograms of standard addition experiments performed for the identification of pomace compounds are provided (PDF)

\section{AUTHOR INFORMATION}

\section{Corresponding Author}

*E-Mail: martin.zehl@univie.ac.at. Phone: +43-1-4277-70700. Fax: +43-1-4277-870700.

\section{ORCID $\odot$}

Verena M. Dirsch: 0000-0002-9261-5293

Martin Zehl: 0000-0001-9685-0373

Notes

The authors declare no competing financial interest.

\section{ACKNOWLEDGMENTS}

This study was funded by the Initiative Group Biopromotion of the University of Vienna. We are thankful to J. Saukel for helpful discussions.

\section{ABBREVIATIONS}

ACCA, $\left[{ }^{14} \mathrm{C}\right]$-L-arginine to $\left[{ }^{14} \mathrm{C}\right]$-L-citrulline conversion assay; $\mathrm{BAEC}$, bovine artery endothelial cell; $\mathrm{CAD}$, charged aerosol detector; $\mathrm{DAD}$, diode array detector; $\mathrm{DCM}$, dichloromethane; DDA, data-dependent acquisition; DER, drug-extract ratio; eNOS, endothelial nitric oxide synthase; EtOAc, ethylacetate; $\mathrm{EtOH}$, ethanol; GP, gradient program; $\mathrm{HCOOH}$, formic acid; HEX, hexane; HUVEC, human umbilical vein endothelial cell; $\mathrm{MeOH}$, methanol; $\mathrm{MeW}$, methanol/water (70:30); NO, nitric oxide; PBS, phosphate-buffered saline; TLC, thin-layer chromatography

\section{REFERENCES}

(1) World Health Organisation. The top 10 causes of death, 2017. http://www.who.int/mediacentre/factsheets/fs310/en/ (Oct 18, 2017).

(2) Gkaliagkousi, E.; Ferro, A. Nitric oxide signalling in the regulation of cardiovascular and platelet function. Front. Biosci. 2011, 16, 18731897.

(3) Bondonno, C. P.; Croft, K. D.; Hodgson, J. M. Dietary nitrate, nitric oxide, and cardiovascular health. Crit. Rev. Food Sci. Nutr. 2016, 56, 2036-2052.

(4) Thilakarathna, S. H.; Rupasinghe, H. P. V. Anti-atherosclerotic effects of fruit bioactive compounds: a review of current scientific evidence. Can. J. Plant Sci. 2012, 92, 407-419.

(5) Ascherio, A.; Hennekens, C.; Willett, W. C.; Sacks, F.; Rosner, B.; Manson, J. A.; Witteman, J.; Stampfer, M. J. Prospective study of nutritional factors, blood pressure, and hypertension among US women. Hypertension 1996, 27, 1065-1072.

(6) Miura, K.; Greenland, P.; Stamler, J.; Liu, K.; Daviglus, M. L.; Nakagawa, $\mathrm{H}$. Relation of vegetable, fruit, and meat intake to 7-year blood pressure change in middle-aged men: the chicago western electric study. Am. J. Epidemiol. 2004, 159, 572-580.

(7) Mozaffarian, D. Dietary and policy priorities for cardiovascular disease, diabetes, and obesity: a comprehensive review. Circulation 2016, 133, 187-225.

(8) Shen, Y.; Croft, K. D.; Hodgson, J. M.; Kyle, R.; Lee, I. L. E.; Wang, Y.; Stocker, R.; Ward, N. C. Quercetin and its metabolites improve vessel function by inducing eNOS activity via phosphorylation of AMPK. Biochem. Pharmacol. 2012, 84, 1036-1044.

(9) Ramirez-Sanchez, I.; Maya, L.; Ceballos, G.; Villarreal, F. (-)-Epicatechin induces calcium and translocation independent eNOS activation in endothelial cells. Am. J. Physiol. Cell Physiol. 2011, 300, C880-C887.

(10) Steinkamp-Fenske, K.; Bollinger, L.; Völler, N.; Xu, H.; Yao, Y.; Bauer, R.; Förstermann, U.; Li, H. Ursolic acid from the Chinese herb Danshen (Salvia miltiorrhiza L.) upregulates eNOS and downregulates Nox4 expression in human endothelial cells. Atherosclerosis 2007, 195, e104-e111.

(11) Kennedy, M.; List, D.; Lu, Y.; Foo, L.; Newman, R.; Sims, P.; Bain, P.; Hamilton, B.; Fenton, G. Apple Pomace and Products from Apple Pomace: Uses, Composition and Analysis. In Modern Methods of Plant Analysis; Linskens, H., Jackson, J., Eds.; Analysis of plant waste material; Springer Verlag: Berlin Heidelberg, 1999; Vol. 20, pp 75119.

(12) Waldbauer, K.; McKinnon, R.; Kopp, B. Apple pomace as potential source of natural active compounds. Planta Med. 2017, 83, 994-1010.

(13) Grigoras, C. G.; Destandau, E.; Fougere, L.; Elfakir, C. Evaluation of apple pomace extracts as a source of bioactive compounds. Ind. Crops Prod. 2013, 49, 794-804.

(14) Sato, M. F.; Vieira, R. G.; Zardo, D. M.; Falcao, L. D.; Nogueira, A.; Wosiacki, G. Apple pomace from eleven cultivars: an approach to identify sources of bioactive compounds. Acta Sci., Agron. 2010, 32, $29-35$.

(15) Schmitt, C. A.; Handler, N.; Heiss, E. H.; Erker, T.; Dirsch, V. $M$. No evidence for modulation of endothelial nitric oxide synthase by the olive oil polyphenol hydroxytyrosol in human endothelial cells. Atherosclerosis 2007, 195, e58-e64.

(16) Waldbauer, K.; Seiringer, G.; Nguyen, D. L.; Winkler, J.; Blaschke, M.; McKinnon, R.; Urban, E.; Ladurner, A.; Dirsch, V. M.; Zehl, M.; Kopp, B. Triterpenoic acids from apple pomace enhance the activity of the endothelial nitric oxide synthase (eNOS). J. Agric. Food Chem. 2016, 64, 185-194.

(17) Wu, X.; Gu, L. W.; Prior, R. L.; McKay, S. Characterization of anthocyanins and proanthocyanidins in some cultivars of Ribes, Aronia, and Sambucus and their antioxidant capacity. J. Agric. Food Chem. 2004, 52, 7846-7856.

(18) Mikulic-Petkovsek, M.; Ivancic, A.; Todorovic, B.; Veberic, R.; Stampar, F. Fruit phenolic composition of different elderberry species and hybrids. J. Food Sci. 2015, 80, C2180-C2190. 
(19) Šavikin, K.; Zdunic, G.; Jankovic, T.; Godjevac, D.; Stanojkovic, T.; Pljevljakusic, D. Berry fruit teas: phenolic composition and cytotoxic activity. Food Res. Int. 2014, 62, 677-683.

(20) Ştefannuţ, M. N.; Cata, A.; Pop, R.; Mosoarca, C.; Zamfir, A. D. Anthocyanins HPLC-DAD and MS characterization, total phenolics, and antioxidant activity of some berries extracts. Anal. Lett. 2011, 44, $2843-2855$.

(21) Makarova, O. V.; Isaev, M. I. Isoprenoids of Sambucus nigra. Chem. Nat. Compd. 1997, 33, 702-703.

(22) Hänsel, R.; Kussmaul, M. Two triterpenes from elder blossoms. Arch. Pharm. 1975, 308, 790-792.

(23) Dzubak, P.; Hajduch, M.; Vydra, D.; Hustova, A.; Kvasnica, M.; Biedermann, D.; Markova, L.; Urban, M.; Sarek, J. Pharmacological activities of natural triterpenoids and their therapeutic implications. Nat. Prod. Rep. 2006, 23, 394-411.

(24) Couloubaly, S.; Delomenie, C.; Rousseau, D.; Paul, J. L.; Grynberg, A.; Pourci, M. L. Fatty acid incorporation in endothelial cells and effects on endothelial nitric oxide synthase. Eur. J. Clin. Invest. 2007, 37, 692-699.

(25) Aguirre-Crespo, F.; Vergara-Galicia, J.; Villalobos-Molina, R.; Javier López-Guerrero, J.; Navarrete-Vázquez, G.; Estrada-Soto, S. Ursolic acid mediates the vasorelaxant activity of Lepechinia caulescens via $\mathrm{NO}$ release in isolated rat thoracic aorta. Life Sci. 2006, 79, 1062-1068.

(26) Lee, A.-W.; Chen, T.-L.; Shih, C.-M.; Huang, C.-Y.; Tsao, N.W.; Chang, N.-C.; Chen, Y.-H.; Fong, T.-H.; Lin, F.-Y. Ursolic acid induces allograft inflammatory factor- 1 expression via a nitric oxiderelated mechanism and increases neovascularization. J. Agric. Food Chem. 2010, 58, 12941-12949.

(27) Rios, M. Y.; López-Martínez, S.; López-Vallejo, F.; MedinaFranco, J. L.; Villalobos-Molina, R.; Ibarra-Barajas, M.; NavarreteVazquez, G.; Hidalgo-Figueroa, S.; Hernández-Abreu, O.; EstradaSoto, S. Vasorelaxant activity of some structurally related triterpenic acids from Phoradendron reichenbachianum (Viscaceae) mainly by NO production: Ex vivo and in silico studies. Fitoterapia 2012, 83, 10231029.

(28) He, X.; Liu, R. H. Triterpenoids isolated from apple peels have potent antiproliferative activity and may be partially responsible for apple's anticancer activity. J. Agric. Food Chem. 2007, 55, 4366-4370.

(29) Yamaguchi, H.; Noshita, T.; Kidachi, Y.; Umetsu, H.; Hayashi, M.; Komiyama, K.; Funayama, S.; Ryoyama, K. Isolation of ursolic acid from apple peels and its specific efficacy as a potent antitumor agent. J. Health Sci. 2008, 54, 654-660.

(30) Vlachojannis, J. E.; Cameron, M.; Chrubasik, S. A systematic review on the Sambuci fructus effect and efficacy profiles. Phytother. Res. 2010, 24, 1-8.

(31) Veberic, R.; Jakopic, J.; Stampar, F.; Schmitzer, V. European elderberry (Sambucus nigra L.) rich in sugars, organic acids, anthocyanins and selected polyphenols. Food Chem. 2009, 114, 511-515.

(32) Hokkanen, J.; Mattila, S.; Jaakola, L.; Pirttila, A. M.; Tolonen, A. Identification of phenolic compounds from lingonberry (Vaccinium vitis-idaea L.), bilberry (Vaccinium myrtillus L.) and hybrid bilberry ( Vaccinium $x$ intermedium Ruthe L.) leaves. J. Agric. Food Chem. 2009, 57, 9437-9447.

(33) McGhie, T. K.; Hudault, S.; Lunken, R. C. M.; Christeller, J. T. Apple peels, from seven cultivars, have lipase-inhibitory activity and contain numerous ursenoic acids as identified by LC-ESI-QTOFHRMS. J. Agric. Food Chem. 2012, 60, 482-491.

(34) Oros, D. R.; Simoneit, B. R. T. Identification of molecular tracers in organic aerosols from temperate climate vegetation subjected to biomass burning. Aerosol Sci. Technol. 1999, 31, 433-445.

(35) Bunea, A.; Rugina, D.; Pintea, A.; Andrei, S.; Bunea, C.; Pop, R.; Bele, C. Carotenoid and fatty acid profiles of bilberries and cultivated blueberries from Romania. Chem. Pap. 2012, 66, 935-939.

(36) Dulf, F. V.; Andrei, S.; Bunea, A.; Socaciu, C. Fatty acid and phytosterol contents of some Romanian wild and cultivated berry pomaces. Chem. Pap. 2012, 66, 925-934. 